\title{
Avaliação das fases cristalinas de dióxido de titânio suportado em cerâmica vermelha
}

\section{(Evaluation of the crystalline phases of supported titanium dioxide in red ceramic)}

\author{
G. T. Saleiro ${ }^{I}$, S. L. Cardoso ${ }^{2}$, R. Toledo ${ }^{3}$, J. N. F. Holanda ${ }^{1}$ \\ ${ }^{1}$ Laboratório de Materiais Avançados, ${ }^{2}$ Laboratório de Ciências Químicas, ${ }^{3}$ Laboratório de Ciências Físicas \\ Universidade Estadual do Norte Fluminense (UENF), Av. Alberto Lamego 2000 \\ Campos dos Goytacazes, RJ 28013-602 \\ gisele-teixeira@oi.com.br
}

\begin{abstract}
Resumo
O dióxido de titânio apresenta boas propriedades como um material fotocatalisador para aplicação em processos de degradação fotocatalítica. No entanto, o dióxido de titânio deve ser usado ancorado num suporte adequado. O uso de cerâmica vermelha como suporte de fotocatalisadores pode ser uma boa alternativa devido ao seu baixo custo e facilidade de fabricação. Neste trabalho foi estudado, via difração de raios X, o dióxido de titânio suportado em cerâmica vermelha produzida com argilas cauliníticas da região de Campos dos Goytacazes, RJ. Os resultados mostram que o dióxido de titânio apresenta mudança estrutural da fase mais fotoativa (anatásio) para a fase menos fotoativa (rutilo) com o aumento da temperatura de sinterização. Em $700{ }^{\circ} \mathrm{C}$ cerca de $50 \%$ da fase anatásio é retida para o dióxido de titânio suportado em cerâmica vermelha, independentemente do tipo de argila usada.

Palavras-chave: dióxido de titânio, DRX, fotocatálise, cerâmica vermelha.
\end{abstract}

\begin{abstract}
The titanium dioxide presents good properties as a photocatalyst material for application in processes of photocatalytic degradation . However, the titanium dioxide should be anchored on a suitable support. The use of red ceramic as supporting material can be an alternative very interesting due to the its low cost and ease of manufacturing. In this work was studied via X-ray diffraction the phase transformation anatase-rutile at different temperatures for supported titanium dioxide in red ceramic substrate prepared with kaolinitic clays from the Campos dos Goytacazes-RJ region. The results showed that the effect of the sintering temperature was promoting the structural change of the phase more photoactive (anatase) for the less photoactive (rutile). At $700{ }^{\circ} \mathrm{C}$ about $50 \%$ of the anatase phase is retained for supported titanium dioxide in red ceramic substrate, independently of the clay type used.
\end{abstract}

Keywords: titanium dioxide, XRD, photocatalysis, red ceramic.

\section{INTRODUÇÃO}

O desenvolvimento industrial de forma rápida e sem planejamento pode acarretar no aumento da degradação ambiental. Além dos danos causados pelo desenvolvimento acelerado, pode ser observada a ocorrência de sérios acidentes tendo como conseqüência a contaminação de mares, rios, lagoas, mangues e solos, por substâncias potencialmente tóxicas e de difícil remediação. Um exemplo são os impactos ambientais causados pelos constantes derrames de petróleo que agridem o meio ambiente. Dentre os métodos convencionais usados no tratamento desses ambientes poluídos se destaca o método da biodegradação. Este método consiste na degradação de óleo por bactérias e fungos presentes no mar e processos químicos. Mais recentemente, os processos oxidativos avançados (POAs) têm despertado grande interesse para remediação de ambientes poluídos. Isto se deve à eficiência em catalisar a oxidação de compostos orgânicos, gerando compostos facilmente biodegradáveis ou mineralizando completamente a matéria orgânica [1].

$\mathrm{O}$ dióxido de titânio $\left(\mathrm{TiO}_{2}\right)$ é a substância mais largamente utilizada no mundo como pigmento branco. Ele é estável quimicamente, não apresenta toxidade e é de custo relativamente baixo. Além disso, apresenta comprimento de onda de absorção de $\lambda=365 \mathrm{~nm}$, que o torna atrativo para aplicações diversas como no melhoramento do brilho, opacidade e alvura na indústria de tintas [2]. Por outro lado, o dióxido de titânio é também um material fotoestável. Este fato tem atraído grande interesse nos últimos anos no uso de $\mathrm{TiO}_{2}$ na oxidação catalítica em função do seu potencial de aplicação na destruição de poluentes em soluções aquosas. $\mathrm{O} \mathrm{TiO}_{2}$ favorece através de oxidações direta e indireta, mecanismos de mineralização total de compostos orgânicos considerados de risco para o meio ambiente. A rigor temse que, $\mathrm{o} \mathrm{TiO}_{2}$ quando em contato íntimo com uma solução aquosa de poluentes, tende a desenvolver um ambiente 
redox capaz de transformá-los em substâncias não tóxicas [3]. O dióxido de titânio pode ser encontrado em três formas cristalinas: anatásio (tetragonal, I4/amd), rutilo (tetragonal, $\mathrm{P}_{2} / \mathrm{mnm}$ ) e bruquita (ortorrômbica, Pcab). Estas formas de $\mathrm{TiO}_{2}$ podem ser minerais naturais ou podem ser preparadas sinteticamente. No entanto, somente as fases anatásio e rutilo são produzidas comercialmente. $\mathrm{O}$ anatásio e bruquita são fases metaestáveis que se transformam exotermicamente e irreversivelmente para o rutilo (fase estável) [4-6]. Em particular a transformação de fase anatásio-rutilo não ocorre numa temperatura de transição definida. Isto é decorrente do fato de não existir um equilíbrio de fase envolvido. Dessa forma a transformação de fase anatásio-rutilo ocorre sobre uma extensa faixa de temperatura compreendida entre $350 \mathrm{e}$ $1175{ }^{\circ} \mathrm{C}$. Em geral a transformação de fase anatásio-rutilo é influenciada pelo método de preparação da amostra, presença de impurezas ou aditivos e pela atmosfera presente durante a transformação.

No processo de degradação fotocatalítica o catalisador $\left(\mathrm{TiO}_{2}\right)$ em forma de pó fino pode ser usado de distintas formas tais como dispersado na solução aquosa (lama), ancorado num suporte adequado, ou ainda num leito fluidizado. No entanto, existe uma preferência para o uso do catalisador ancorado num suporte adequado [7]. Um suporte adequado para o $\mathrm{TiO}_{2}$ deve apresentar os seguintes requisitos: a) boa estabilidade mecânica; b) ser transparente a radiação UV; c) favorecer forte ligação físico-química com as partículas de $\mathrm{TiO}_{2}$, sem afetar negativamente a reatividade delas; d) apresentar alta área superficial; e) apresentar boa capacidade de adsorção para os compostos orgânicos a serem degradados; f) apresentar configuração física que favoreça a separação fase sólidafase líquida; g) facilitar processos de transferência de massa; e h) ser quimicamente inerte. Diversos materiais têm sido estudados como substrato para suportar o catalisador $\left(\mathrm{TiO}_{2}\right)$ para fotodegradação de poluentes tais como sílica, sílica gel, zeólitas, membranas cerâmicas, membranas de celulose microporosas, vidro pyrex, fibra de vidro, fibra ótica de quartzo, aço inoxidável, ferro anodizado e filmes de polietileno.

O uso de cerâmica vermelha como suporte poroso para o catalisador pode ser uma excelente alternativa aos materiais normalmente utilizados, principalmente em função do seu baixo custo, facilidade de fabricação e permeabilidade. Outro fator muito importante é a disponibilidade de grandes depósitos de matérias-primas argilosas (argilas comuns). Em particular na região Norte Fluminense, no município de Campos dos Goytacazes, existem importantes depósitos de argilas predominantemente cauliníticas [8-10]. Estas argilas contêm também quantidades apreciáveis de sílica na forma de quartzo livre como mineral acessório.

No presente trabalho o objetivo principal é a avaliação das fases cristalinas do dióxido de titânio suportado em substrato de cerâmica vermelha produzido em diferentes temperaturas.

\section{MATERIAIS E MÉTODOS}

As matérias-primas usadas neste trabalho foram dióxido de titânio e duas argilas comuns. Foi usado um dióxido
Tabela I - Composição química das argilas vermelhas (\%). [Table I - Chemical composition of the red clays (\%).]

\begin{tabular}{ccc}
\hline Compostos & Argila A1 & Argila A2 \\
\hline $\mathrm{SiO}_{2}$ & 37,70 & 42,40 \\
$\mathrm{Al}_{2} \mathrm{O}_{3}$ & 32,77 & 33,69 \\
$\mathrm{Fe}_{2} \mathrm{O}_{3}$ & 11,80 & 5,19 \\
$\mathrm{~K}_{2} \mathrm{O}$ & 2,28 & 0,97 \\
$\mathrm{CaO}$ & 0,24 & 0,45 \\
$\mathrm{TiO}$ & 1,96 & 1,62 \\
Perda ao fogo a & 13,04 & 15,44 \\
$1000{ }^{\circ} \mathrm{C}$ & & \\
\hline
\end{tabular}

de titânio de alta pureza (mín. 99\%) em forma de pó fino (tipo $\mathrm{TiO}_{2}$ P-25) fornecido pela Degussa, contendo 70\% da fase anatásio. As argilas sedimentares utilizadas neste trabalho foram coletadas numa empresa cerâmica do pólo ceramista de Campos dos Goytacazes, RJ, as quais são normalmente usadas na fabricação de produtos de cerâmica vermelha (tijolos, blocos cerâmicos e telhas). As argilas foram destorroadas e submetidas a peneiramento para a fração < 200 mesh (74 $\mu \mathrm{m}$ ASTM). A Tabela I apresenta a composição química das argilas.

Na preparação das amostras de trabalho foi utilizada aproximadamente $20 \mathrm{~g}$ de argila para cada concentração de $\mathrm{TiO}_{2}(\mathrm{C} 1=0 \%$ em peso (argilas puras); $\mathrm{C} 2=15 \% \mathrm{em}$ peso; e $\mathrm{C} 3=30 \%$ em peso). As argilas (argila A1 e argila A2) e o dióxido de titânio nas proporções pré-determinadas foram misturados e homogeneizados com uma quantidade adequada de água destilada, para formação de uma massa coesiva com consistência plástica.

Pastilhas de cerâmica vermelha foram preparadas por extrusão com formato cilíndrico de $3 \mathrm{~mm}$ de diâmetro e $11 \mathrm{~mm}$ de altura. Após conformação, as pastilhas foram colocadas para secar a temperatura ambiente em recipiente de alumínio envolvido em papel de filme de PVC para evitar contaminação com o meio. O período de secagem natural foi de uma semana. Em seguida as pastilhas foram submetidas à secagem em estufa por $18 \mathrm{~h}$ a $110{ }^{\circ} \mathrm{C}$. As pastilhas de cerâmica vermelha foram queimadas em forno elétrico tipo mufla. As temperaturas de patamar usadas foram $250{ }^{\circ} \mathrm{C}$, $500{ }^{\circ} \mathrm{C}$ e $700{ }^{\circ} \mathrm{C}$, com as pastilhas mantidas na temperatura de patamar durante $1 \mathrm{~h}$. O resfriamento foi feito a partir do desligamento do forno até retornar a temperatura ambiente. A Tabela II apresenta o esquema de queima das pastilhas.

As pastilhas de cerâmica vermelha queimadas foram cominuídas, peneiradas (200 mesh) e depositadas em lâminas de vidro. Em seguida foram submetidas à análise por difração de raios $\mathrm{X}$ em um difratômetro convencional (Seifert URD 65). A radiação empregada foi a $\operatorname{Cok}_{\alpha}(\lambda=1,78897 \AA)$ com filtro de ferro, a $40 \mathrm{kV}$ e $30 \mathrm{~mA}$. A varredura $(2 \theta$ de 6 a $70^{\circ}$ ) foi feita com passo $0,02^{\circ}(2 \theta)$ por $2 \mathrm{~s}$ de tempo por passo. As fases cristalinas foram identificadas por meio da comparação do ângulo de Bragg, distância interplanar (hkl) e da intensidade relativa dos principais picos de difração com os valores tabelados pelo Joint Committee of Powder Diffraction Standards (JCPDS). O método de Rietveld [11] 
Tabela II - Esquema de queima das amostras cerâmicas. [Table II - Outline of firing of the ceramic samples.]

\begin{tabular}{cc}
\hline Temperatura $\left({ }^{\circ} \mathrm{C}\right)$ & Identificação das amostras \\
\hline \multirow{2}{*}{250} & A1C1T1, A1C2T1, \\
& A1C3T1, A2C1T1, \\
& A2C2T1, A2C3T1 \\
& A1C1T2, A1C2T2, \\
& A1C3T2, A2C1T2, \\
& A2C2T2, A2C3T2 \\
& A1C1T3, A1C2T3, \\
& A1C3T3, A2C1T3, \\
& A2C2T3, A2C 3T3 \\
\hline
\end{tabular}

foi usado para quantificar as fases cristalinas nas pastilhas de cerâmica vermelha queimadas.

\section{RESULTADOS E DISCUSSÃO}

Na Fig. 1 são apresentados os difratogramas de raios $\mathrm{X}$ para o dióxido de titânio puro em diferentes temperaturas. Nota-se que à medida que se aumenta a temperatura, os picos da fase rutilo vão ficando cada vez mais intensos. Este comportamento confirma a assertiva para a transformação de fase do anatásio para o rutilo [5].

As Figs. 2 e 3 apresentam os difratogramas de raios $X$ para o dióxido de titânio suportado em substrato de cerâmica vermelha preparado com a argila A1, para as temperaturas de 250 e $700{ }^{\circ} \mathrm{C}$, respectivamente. A amostra A1C1 corresponde à argila $\mathrm{A} 1$ pura a temperatura ambiente. Verifica-se que a argila A1 é constituída dos argilominerais caulinita $\left(\mathrm{Al}_{2} \mathrm{O}_{3} \cdot 2 \mathrm{SiO}_{2} \cdot 2 \mathrm{H}_{2} \mathrm{O}\right)$ e illita/mica, com predominância de caulinita. É por essa razão que as argilas sedimentares da

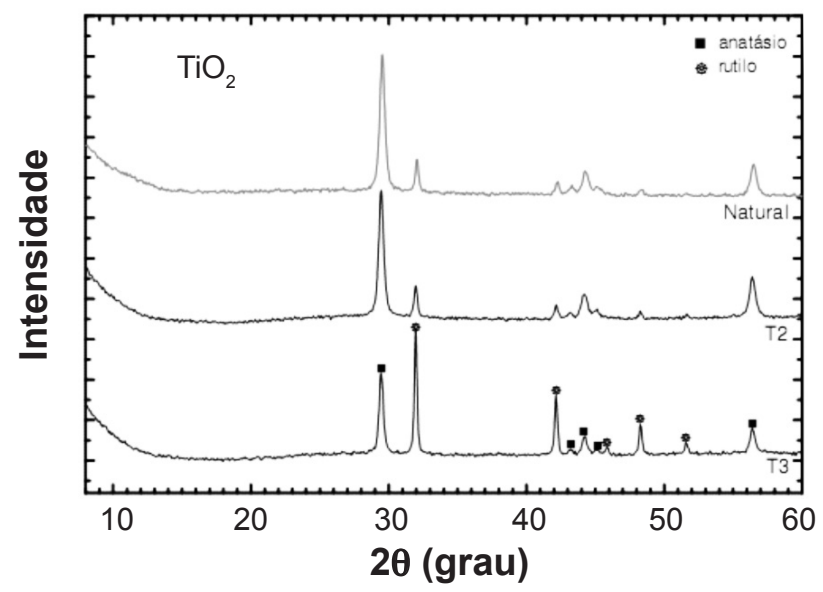

Figura 1: Difratogramas de raios $\mathrm{X}$ do dióxido de titânio puro tratado em diferentes temperaturas: $25^{\circ} \mathrm{C}$ (natural), $\mathrm{T} 2=500{ }^{\circ} \mathrm{C}$ e T3 $=700{ }^{\circ} \mathrm{C}$.

[Figure 1:XRD patterns of the titanium dioxide treated in different temperatures: $25^{\circ} \mathrm{C}$ (natural), $\mathrm{T} 2=500^{\circ} \mathrm{C}$, and $\left.\mathrm{T3}=700^{\circ} \mathrm{C}.\right]$

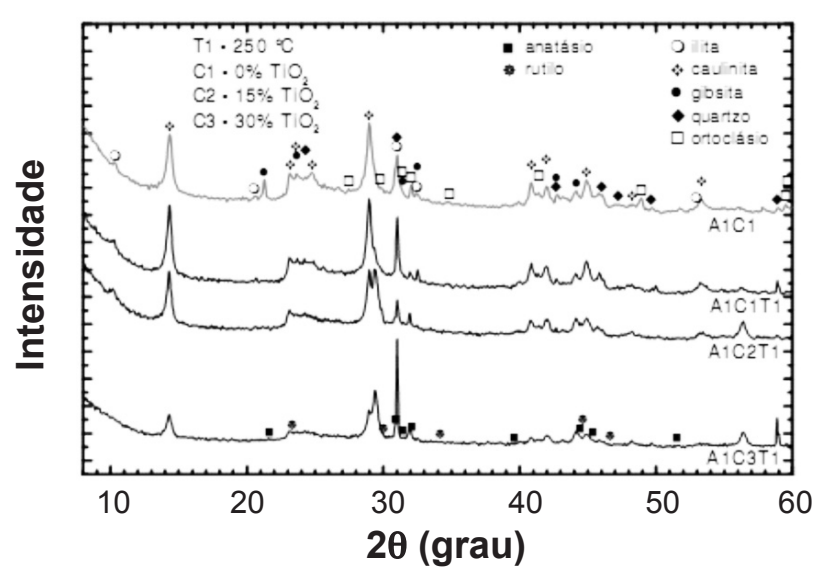

Figura 2: Difratogramas de raios $\mathrm{X}$ do dióxido de titânio suportado em cerâmica vermelha preparada com a argila $\mathrm{A} 1 \mathrm{em} \mathrm{T} 1=250{ }^{\circ} \mathrm{C}$. [Figure 2: XRD patterns of the supported titanium dioxide in red ceramic prepared with clay $\mathrm{Al}$ at $\mathrm{Tl}=250^{\circ} \mathrm{C}$.]

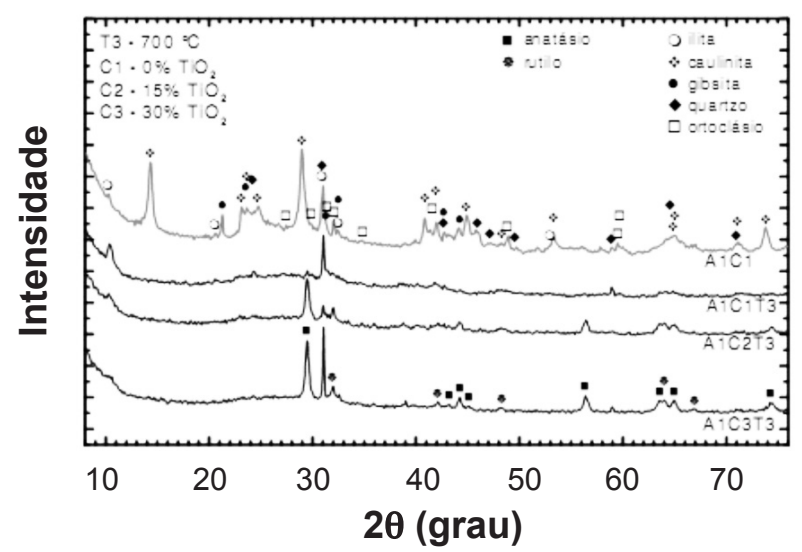

Figura 3: Difratogramas de raios $\mathrm{X}$ para o dióxido de titânio suportado em cerâmica vermelha preparada com a argila A1 em $\mathrm{T} 3=700{ }^{\circ} \mathrm{C}$.

[Figure 3: XRD patterns of the supported titanium dioxide in red ceramic prepared with clay $\mathrm{Al}$ at $\mathrm{T} 3=700^{\circ} \mathrm{C}$.]

região de Campos dos Goytacazes-RJ são denominadas de argilas predominantemente cauliníticas [12]. Notam-se também as presenças de fases cristalinas tais como quartzo $\left(\mathrm{SiO}_{2}\right)$ e gibsita $\left(\mathrm{Al}_{2} \mathrm{O}_{3} \cdot 3 \mathrm{H}_{2} \mathrm{O}\right)$ como minerais acessórios. Há indícios também das presenças de ortoclásio (feldspato potássico) e goetita. Os resultados da análise por difração de raios X estão de acordo com os dados de composição química da argila A1 (Tabela I). É importante destacar que embora a argila A1 apresente pequena quantidade de $\mathrm{TiO}_{2}$ $(1,96 \%)$, o mesmo não foi identificado no difratograma de raios X. A argila A1 contém também quantidade apreciável de óxido de ferro $(11,80 \%)$, que é responsável pela coloração avermelhada das peças cerâmicas após queima. Ressaltase que nas argilas de Campos dos Goytacazes, RJ, cátions $\mathrm{Fe}^{3+}$ podem parcialmente substituir cátions $\mathrm{Al}^{3+}$ na folha octaédrica da estrutura da caulinita [13].

Quando o substrato de cerâmica vermelha é sinterizado até $250{ }^{\circ} \mathrm{C}$ (amostra $\mathrm{A} 1 \mathrm{C} 1 \mathrm{~T} 1$ ), as fases cristalinas são 
praticamente as mesmas identificadas anteriormente para temperatura ambiente. A rigor ocorreram somente pequenas alterações nas intensidades de alguns picos de difração. Com a introdução do dióxido de titânio no suporte de cerâmica vermelha (amostras A1C2T1 e A1C3T1), notamse as fases anatásio e rutilo. As intensidades de alguns picos, em particular os picos principais da caulinita, foram influenciadas pelas presenças das fases anatásio e rutilo. Quanto maior a quantidade de dióxido de titânio adicionado, menor a intensidade dos picos da caulinita. Quando a temperatura de sinterização é aumentada até $700{ }^{\circ} \mathrm{C}$, o difratograma de raios $\mathrm{X}$ é modificado. Nesta temperatura os picos da caulinita desapareceram devido à desidroxilação da caulinita para formação da metacaulinita amorfa [14]. Os picos da gibsita também desapareceram para formação de uma alumina de transição [15]. Nota-se ainda que com a amorfização da caulinita, os picos referentes ao anatásio e rutilo foram realçados.

As Figs. 4 e 5 apresentam os difratogramas de raios $\mathrm{X}$ do dióxido de titânio suportado em cerâmica vermelha produzida com a argila A2, para 250 e $700{ }^{\circ} \mathrm{C}$, respectivamente. $\mathrm{O}$ comportamento das fases cristalinas é muito similar ao observado anteriormente para o suporte de cerâmica vermelha produzido com a argila A1.

As Figs. 6 e 7 apresentam as comparações dos difratogramas de raios $\mathrm{X}$ em 3D para o dióxido de titânio e as amostras A1C2 e A2C2 sinterizadas em 500 e $700{ }^{\circ} \mathrm{C}$, respectivamente. Como observado anteriormente, o efeito da temperatura de sinterização sobre a transformação de fase anatásio-rutilo para o dióxido de titânio puro é evidente. Observa-se nessas figuras que para o dióxido de titânio puro a $500{ }^{\circ} \mathrm{C}$ a fase anatásio é amplamente majoritária, enquanto que a $700{ }^{\circ} \mathrm{C}$ a fase majoritária é o rutilo. Por outro lado, nota-se também que quando o dióxido de titânio está suportado no substrato de cerâmica vermelha a transformação anatásio-rutilo tende a ocorrer com menor intensidade. Este comportamento pode estar relacionado provavelmente à composição mineralógica

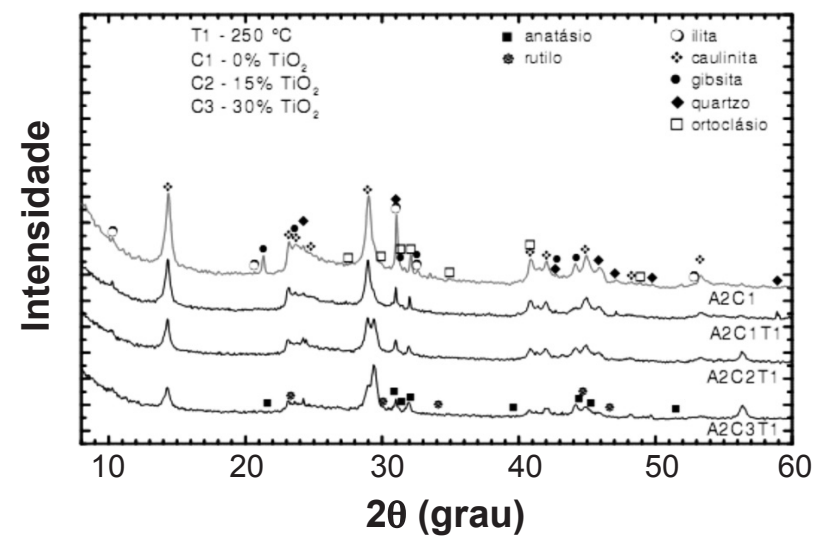

Figura 4: Difratogramas de raios X para o dióxido de titânio suportado em cerâmica vermelha preparada com a argila A2 em $\mathrm{T} 1=250^{\circ} \mathrm{C}$.

[Figure 4: XRD patterns of the supported titanium dioxide in red ceramic prepared with clay $A 2$ at $T 1=250{ }^{\circ} \mathrm{C}$.]

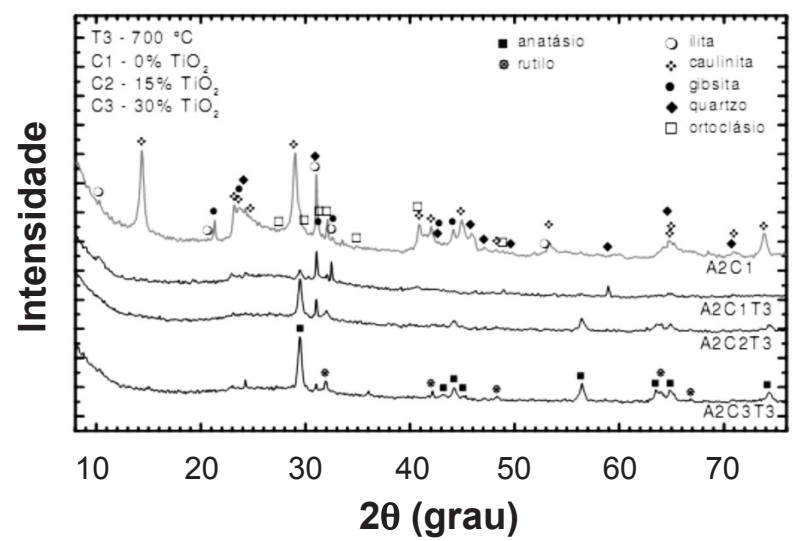

Figura 5: Difratogramas de raios $\mathrm{X}$ para o dióxido de titânio suportado em cerâmica vermelha preparada com a argila A2 em $\mathrm{T} 3=700{ }^{\circ} \mathrm{C}$.

[Figure 5: XRD patterns of the supported titanium dioxide in red ceramic prepared with clay $\mathrm{A} 2$ at $\mathrm{T} 3=700^{\circ} \mathrm{C}$.]

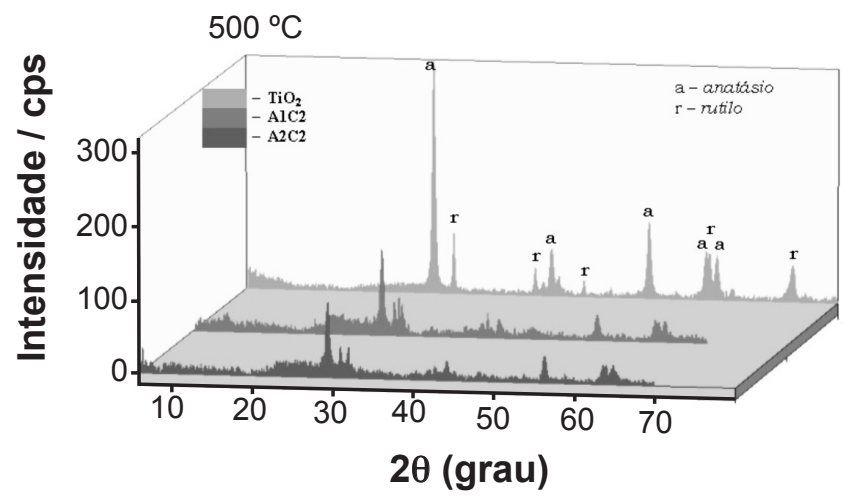

Figura 6: Difratogramas de raios $\mathrm{X}$ do dióxido de titânio e as amostras A1C2 e A2C2 sinterizadas em $500{ }^{\circ} \mathrm{C}$.

[Figure 6: XRD patterns of the titanium dioxide and samples $A 1 C 2$ and $A 2 C 2$ sintered at $500{ }^{\circ} \mathrm{C}$.]

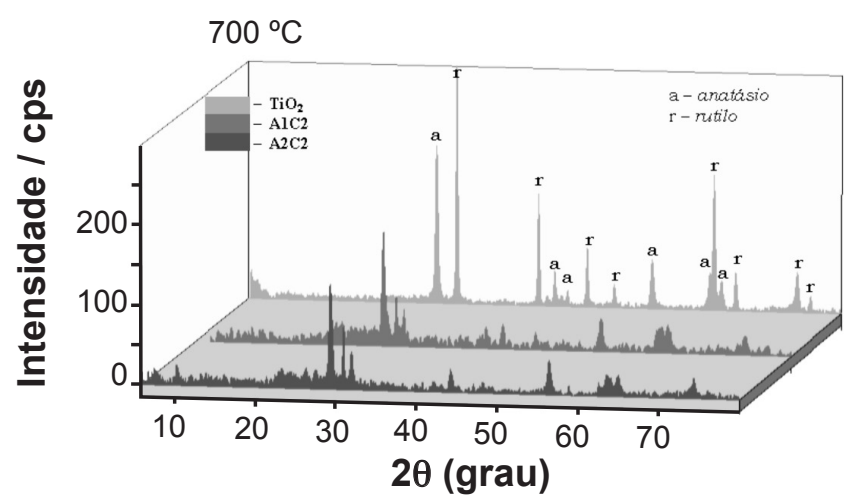

Figura 7: Difratogramas de raios $\mathrm{X}$ do dióxido de titânio e as amostras A1C2 e A2C2 sinterizadas em $700{ }^{\circ} \mathrm{C}$.

[Figure 7: XRD patterns of the titanium dioxide and samples A1C2 and $\mathrm{A} 2 \mathrm{C} 2$ sintered at $700^{\circ} \mathrm{C}$.]

das argilas usadas, que são materiais poliminerálicos. A presença de determinadas impurezas podem acelerar ou retardar a transformação de fase anatásio-rutilo, devido o aumento ou redução da concentração de vacâncias de 


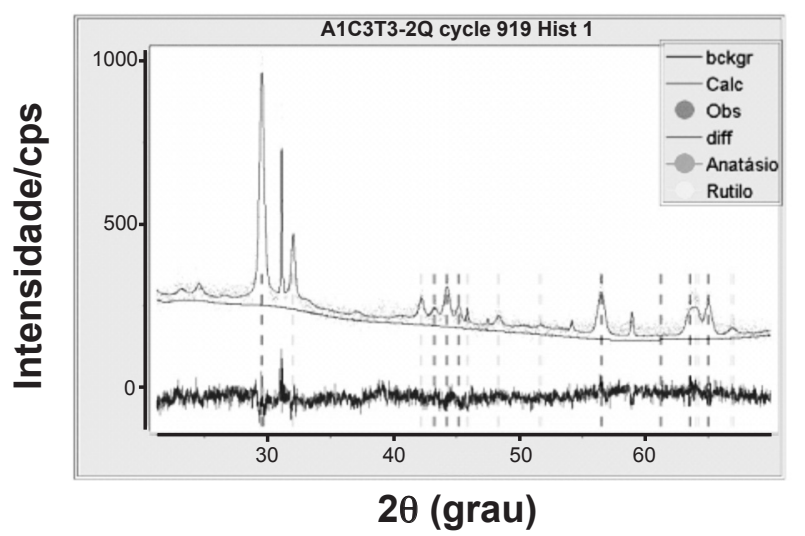

Figura 8: Análise por difração de raios $\mathrm{X}$ da amostra A1C3 sinterizada em $700{ }^{\circ} \mathrm{C}$ e refinada via método de Rietveld.

[Figure 8: XRD analysis of the sample AlC3 sintered at $700{ }^{\circ} \mathrm{C}$, and refined via Rietveld method.]

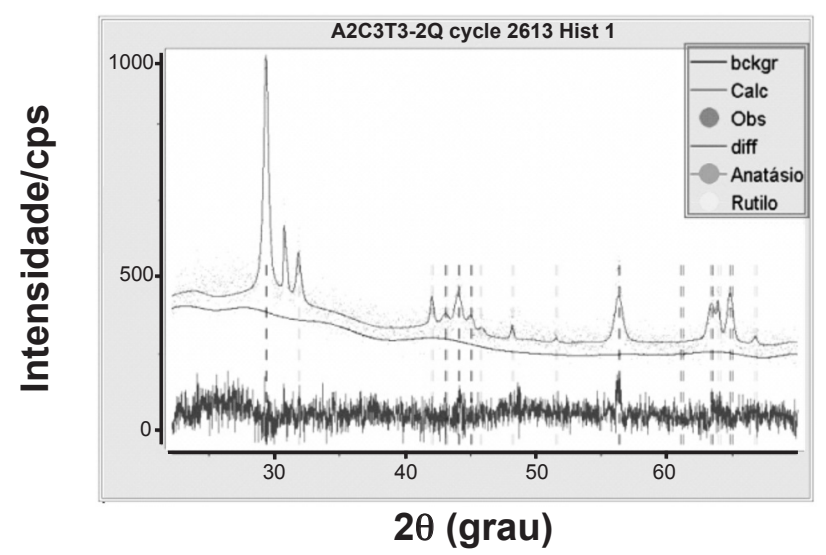

Figura 9: Análise por difração de raios X para a amostra A2C3 sinterizada em $700{ }^{\circ} \mathrm{C}$ e refinada via método de Rietveld.

[Figure 9: XRD analysis of the sample A2C3 sintered at $700{ }^{\circ} \mathrm{C}$, and refined via Rietveld method.]

Tabela III - Fases cristalinas obtidas pelo refinamento de Rietveld para as amostras A1C3T3 e A2C3T3.

[Table III - Crystalline phases obtained through Rietveld method for the samples AIC3T3 and A2C3T3.]

\begin{tabular}{ccc}
\hline Amostras & Fase cristalina & \% em massa \\
\hline A1C3T3 & anatásio & 50,5 \\
& rutilo & 17,6 \\
& quartzo & 22,1 \\
& illita/mica & 9,7 \\
A2C3T3 & anatásio & 50,9 \\
& rutilo & 13,7 \\
& quartzo & 17,0 \\
& illita/mica & 18,4 \\
\hline
\end{tabular}

oxigênio na rede cristalina do $\mathrm{TiO}_{2}[16]$.

As Figs. 8 e 9 ilustram a utilização do método de Rietveld para o refinamento dos difratogramas de raios $\mathrm{X}$ das amostras sinterizadas a $700{ }^{\circ} \mathrm{C}$ durante $1 \mathrm{~h} \mathrm{~A} 1 \mathrm{C} 3 \mathrm{e}$ A2C3, respectivamente. Na Tabela III são apresentados os resultados da análise semi-quantitativa das fases cristalinas presentes nas amostras estudadas. A fase anatásio é a fase cristalina majoritária com cerca de $50 \%$, independentemente do tipo de argila usada. Isto é importante devido à fase anatásio ser a fase mais fotoativa do dióxido de titânio, que é altamente desejável em processos de degradação fotocatalítica. Além do mais, dentre as temperaturas testadas, $700{ }^{\circ} \mathrm{C}$ parece ser a mais indicada para obtenção de um suporte poroso de cerâmica vermelha com uma boa resistência mecânica. Nesta temperatura já ocorre à sinterização inicial da argila com a formação dos pescoços interpartículas via mecanismos de sinterização de estado sólido, provavelmente por difusão superficial [17]. De forma que a cerâmica vermelha tem potencial para ser usado como um bom material de substrato poroso para suportar o fotocatalisador $\left(\mathrm{TiO}_{2}\right)$.

\section{CONCLUSÕES}

A cerâmica vermelha sinterizada a $700{ }^{\circ} \mathrm{C}$ possui boa capacidade para suportar o material fotocatalisador dióxido de titânio. Foi possível acompanhar por difração de raios X a evolução da transformação de fase anatásio-rutilo a partir do dióxido de titânio suportado em cerâmica vermelha sinterizada. Verifica-se que o efeito da temperatura de sinterização é o de promover a transformação da fase anatásio para a fase rutilo, enquanto que o suporte de cerâmica vermelha aparentemente tende a inibir essa transformação. Para $700^{\circ} \mathrm{C}$ a fase anatásio é a fase cristalina majoritária com cerca de $50 \%$ para ambas as argilas estudadas. Ela é a fase mais fotoativa do dióxido de titânio. A retenção dessa fase é importante para o uso do dióxido de titânio em fotocatálise.

\section{AGRADECIMENTOS}

Ao CNPq e a FAPERJ pelo apoio financeiro.

\section{REFERÊNCIAS}

[1] EPA, Environmental Protection Agency, Handbook Advanced Photochemical Oxidation Processes, Cincinnati, EUA (1998).

[2] J. G. Santos, E. E. Melo, J. W. D. Cunha, T. Ogasawara, Anais do XV CBECIMAT, Natal, RN (2002) 71-76.

[3] D. Chatterjee, A. Mahata, Catal. Comm. 2,1 (2001) 1-3.

[4] C. N. Rao, S. R. Yoganarasimhan, P. A. Falth, Trans. Farad. Soc. 57 (1961) 504.

[5] D. Dabler, A. Feltz, J. Jung, W. Ludwig, E. Kaiserberger, J. Therm. Anal. 33 (1988) 803-809.

[6] P. S. Há, H. J. Youn, H. C. Jung, J. Colloid Inter. Sci. 223 (2000) 16-20.

[7] R. L. Pozzo, M. A. Baltanás, A. E. Cassano, Catal. Today 39 (1997) 219-231.

[8] J. Alexandre, F. Saboya, B. C. Marques, M. L. P. Ribeiro, C. Salles, M. G. Silva, M. S. Sthel, L. T. Auler, H. Vargas, The Analyst 124 (1999) 1209-1214.

[9] C. M. F. Vieira, J. N. F. Holanda, D. G. Pinatti, Cerâmica 
46, 297 (2000) 14-17.

[10] G. P. Souza, R. Sánchez, J. N. F. Holanda, Cerâmica 48, 306 (2002) 102-107.

[11] D. M. Moore, D. L. Reynolds Jr., X-Ray Diffraction and the Identification and Analysis of Clay Minerals, $2^{\text {nd }} \mathrm{Ed}$., Oxford Univ. Press, New York, EUA (1997).

[12] F. A. C. Milheiro, M. N. Freire, A. G. P. Silva, J. N. F. Holanda, Ceram. Int. 31 (2005) 757-763.

[13] R. S. T. Manhães, L. T. Auler, M. S. Sthel, J. Alexandre, M. S. O. Massunaga, J. G. Carrió, D. R. Santos, E. C. Silva, A. Garcia-Quiroz, H. Vargas, Appl. Clay Sci. 21 (2002) 303-
311.

[14] P. S. Santos, Ciência e Tecnologia das Argilas, 2a Ed., vol. 1, Editora Edgard Blücher Ltda., S. Paulo, SP (1989).

[15] J. W. Hollaron, Calcination, Engineered Materials Handbook - Ceramics and Glass, vol. 4, ASM International, EUA (1991).

[16] F. C. Gennari, D. M. Pasquevich, J. Mater. Sci. 33, 6 (1998) 1571-1578.

[17] W. D. Kingery, M. Berg, J. Appl. Phys. 26, 10 (1955) 1205-1212.

(Rec. 29/05/2009, Ac. 28/08/2009) 